\title{
The Use of a Shear Device to Monitor the Stability of a Single-Chain Variable Fragment (scFv) Fusion Protein MFECP1
}

\author{
Peter Blas \\ The Kibworth School, Kibworth Beauchamp, United Kingdom
}

Email address:

peter_blas@hotmail.com, pblas@thekibworthschool.org

\section{To cite this article:}

Peter Blas. The Use of a Shear Device to Monitor the Stability of a Single-Chain Variable Fragment (scFv) Fusion Protein MFECP1. Bioprocess Engineering. Special Issue: Advances in Biochemical Engineering and Biotechnology. Vol. 4, No. 1, 2020, pp. 29-38. doi: $10.11648 /$ j.be. 20200401.15

Received: March 17, 2020; Accepted: April 22, 2020; Published: May 29, 2020

\begin{abstract}
Antibody based drugs are increasingly being used to treat a vast array of diseases because of their unique affinity to target specific antigen proteins on the surfaces of target cancer cells. Fusions of antibodies and conjugated biopharmaceuticals are progressively being used as this gives the opportunity to target other cytotoxic molecules to unwanted cells. It is critical to ensure these types of drug products are not fragile or uneconomical to produce at a large scale. A very small amount of precious protein solution can be characterised in an Ultra scale-down (USD) shear device to uncover if fusion proteins are prone to shear stress. This article presents how the purified and deglycosylated form of the MFECP1 fusion protein was quantified with an ELISA from $700-50 \mathrm{ng} / \mathrm{ml}$, with a $+/-10 \%$ deviation in the standard curve. It also describes how the same MFECP1 fusion protein was analysed to establish the optimum experimental control conditions that were required to observe changes due to hydrodynamic-associated degradation in a shear device. Lastly, it looks at how a first order kinetic relationship can be used to model the rate of MFECP1 fusion protein degradation and how this was used to quantify the rate of protein loss during different shear environments with and without air/liquid interfaces.
\end{abstract}

Keywords: Ultra Scale-down, Shear Device, Degradation, Fusion Proteins, USD

\section{Introduction}

The advancement of modern medicine has propagated an ageing population; disorders like cancer, dementia and neurodegradative diseases are becoming more common and are difficult to treat with traditional synthetic chemical compounds. These diseases require the manufacture of very complicated biopharmaceuticals; fusion proteins and conjugated drugs $[1,2,16,22]$. Fusion proteins can treat the problems but these therapeutics tend to be sensitive to shear degradation during their large scale bioprocessing. Detailed characterisation of these therapeutic proteins is important as this can inform a bioprocess engineer of the optimum large scale working parameters, which can result towards increasing yields [28].

Various research groups past and present have documented that proteins plasmids and enzymes are disrupted by shear [4, 9, 10, 15 18]. Some have suggested that the degradation could be a combination of shear and air/liquid interfaces [5, 13, 19, 20]. Several modern therapeutics Her 2 and fusions are examples of conjugated therapeutics that could encounter significant more breakdown due to their fragile structural nature. [3, 6, 14]. Better understanding of how these complexes breakdown and how they can be minimised, would help a process engineer to improve the large scale bioprocessing of biopharmaceuticals. An example of this type of research can be found in the work cover by $[5,11]$ where it was found that ultra scale-down techniques have uncovered shear protectants that could be added to the large scale process to improve yield impurities.

It has been discovered that some proteins do suffer from shear stress but some do not, differences in these results could be due to the diversity in protein structures and or differences in the quaternary structure of proteins $[17,26$, 27]. The varied amino acid sequences of different proteins and diverse external environments the proteins encounter 
during their bioprocessing, could all play a factor into the reasons why protein break down or are deactivated [12].

It is common knowledge that enzymes and fusions of biopharmaceuticals can undergo shear sensitive degradation and/or deactivation [20, 32, 27, 29]. But it is very unclear on the exact mechanism of deactivation, however protein therapeutics are broken down and it can be assumed that they all follow different kinetic relationships because different types of proteins are involved.

Oliva in 2003 proposed a first order relationship; Harrison in 1998 proposed a second order model and Lencki in 1993 proposed more complex protein degradation pathways. It is not unusual that there are varying ideas as they have all used different protein constructs so one would assume that they would undergo different rates of protein deactivation or degradation [29]. The important part of the research is to quantify accurately how this is happening, using accurate scientific strategies as outlined in this communication. Significant research into this field should expose precisely how proteins interact in a shear environment and this information could be used to improve protein yields at large scale [25].

The current article explain how characterisation of a Sc single-chain variable fragment $(\mathrm{scFv})$ fusion protein MFECP1 can be examined in a rotating disc shear device to help uncover parameters that induces break down and actions that could be taken on the large scale to reduce impurities and increase yields [6]. Firstly, it examines at how the purified deglycosylated fusion protein may best be quantified and explains why a ELISA was used to analyse the fraction of degraded protein in sheared samples from the device. This publication also describes how the same MFECP1 fusion protein was used to establish the optimum experimental control conditions that are required to observe changes due to shear-associated degradation in a shear device. Lastly it looks at how a first order kinetic relationship was used to model the rate of MFECP1 fusion protein degradation and how this was used to quantify the rate of protein loss during different shear environments with and without air/liquid interfaces.

\section{Materials and Methods}

\subsection{Laboratory Consumables}

Most laboratory equipment, disposables, plastic flasks and glass containers were acquired from Fisher Scientific Ltd, (Leicestershire, UK) these were of the premium analytical grade.

\subsection{Chemicals and Reagents}

The chemicals, used were purchased from Sigma Aldrich (Dorset, UK) and were of premium analytical grade. The Royal Free Hospital, (Oncology, UK) supplied the following reagents, carcinoma-embryonic antigen (CEA), NA1 polyclonal anti-CPG $\mathrm{CP}_{2}$ primary antibody and anti-MFE antibody.

\subsection{Water for Injection (WFI)}

Sterile water for injection (Baxter, UK) was used primarly in the fermentation of the recombinant fusion protein (MFECP1). Pure de-ionized water (18.2 $\Omega$, Milli-Q system) was employed for downstream purification steps and for ultra scale-down shear experiments.

\subsection{Microorganism Strain}

The X33 Pichia pastoris working cell bank was supplied by The Royal Free Hospital, (Oncology, UK) and was stored at $80^{\circ} \mathrm{C}$ in a class $\mathrm{C}$ GMP area sterile water for irrigation (Baxter, $\mathrm{UK}$ ) was used in the fermentation production of the recombinant antibody fusion protein (MFECP1). Ultra pure de-ionized water (18.2 $\Omega$, Milli-Q system) was used for downstream purification steps and for all USD shear experiments.

\subsection{Bioanalyser Protein 210}

The Agilent Bioanalyser Protein 210 system and the associated protein 200 assay kit was used to analyse all protein samples, this technique separated proteins by size to charge ratio. The gel-dye mix solution was prepared by mixing $25 \mu \mathrm{L}$ of a protein 200 dye concentrate with $650 \mu \mathrm{L}$ of plus gel matrix, mixed on a vortex machine and centrifuged at 15,000 rpm for 15 seconds. Note it was critical that this gel-dye mix was stored away from light. Next, the destaining solution was prepared by placing $650 \mu \mathrm{L}$ of plus gel matrix into the top of an Eppendorf spin filter tube and was centrifuged (Beckman coulter bench top centrifuge X-22, USA) for 15 minutes at 5,200 rpm. Denaturing solution was prepared by adding $7 \mu \mathrm{L}$ of deionised water to 200 $\mu \mathrm{L}$ of protein 200 buffer and vortexing for 5 seconds.

The assay protocol is as follows: pipette $4 \mu \mathrm{L}$ of the test protein sample into $2 \mu \mathrm{L}$ of the denaturing solution in a 0.5 $\mathrm{mL}$ microcentrifuge tube, mix well and centrifuge for 15 seconds at 15,000 rpm. Next prepare the ladder by pipetting 6 $\mu \mathrm{L}$ of the ladder solution from the kit into a $0.5 \mathrm{~mL}$ microcentrifuge tube. Denature the proteins by heating all the

samples to $100^{\circ} \mathrm{C}$ for 5 minutes. After the microcentrifuge tubes have cooled down pipette $84 \mu \mathrm{L}$ of deionised water into the protein solutions and vortex for 15 seconds. Load the protein 200 chip initially with $12 \mu \mathrm{L}$ of gel-dye mix into well $\mathrm{G}$, set the plunger to $1 \mathrm{~mL}$ and prime station $\mathrm{G}$, by pushing down on the plunger for 60 seconds. Remove excess gel-dye mix from the well and pipette a further $12 \mu \mathrm{L}$ of gel-dye mix into all wells marked $\mathrm{G}$, on the chip. Load $12 \mu \mathrm{L}$ of destaining solution into the wells marked DS and pipette 6 $\mu \mathrm{L}$ of all the protein samples that require analysis in wells 1 10. Next add $6 \mu \mathrm{L}$ of the denatured ladder to the wells marked L. After this the chip is ready to be analysed and is placed into the Agilent Bioanalyser.

\subsection{Preparation of MFECP1 Fusion Protein Stocks}

All MFECP1 fusion protein stock solutions were prepared in a $0.01 \mathrm{M}$ phosphate buffer saline solution at $\mathrm{pH} 7.4$ (PBS) $0.138 \mathrm{M} \mathrm{NaCl} ; 0.0027 \mathrm{M} \mathrm{KCl}$ and made up with ultra pure deionized water $\mathrm{v} / \mathrm{v}$ (18.2 $\Omega$, Milli-Q system). MFECP1 fusion 
protein stock solutions were made up to around, $500 \mathrm{ng} / \mathrm{mL}$ and were stored on ice when not in use during shear experiments. Fully protocolled GMP fermentations as described in [30, 31] and downstream processing as described in (31), were performed in the Copey May Production Unit at the Royal free Hospital, London to produce the fusion protein for all shear experiments

\subsection{Ultra Scale-down (USD) Experiments}

MFECP1 fusion protein was subjected to controlled levels of shear in an ultra scale-down rotating disc shear device. The device was fabricated from 316 stainless steel in house (Mechanical Engineering Workshop, UCL, London) and comprised of a rotating disc housed inside a shear chamber. The dimensions of the rotating disc were; radius of disc $=0.0400 \mathrm{~m}$, thickness of disc $=0.0015 \mathrm{~m}$. The disc was attached to a $7.2 \mathrm{~V} 500 \mathrm{BB}$ race VS Motor (Graupner, Germany) by a stainless steel shaft through a white polytetra-fluoro-ethylene (PTFE) seal. The dimensions of the internal shear chamber were; diameter $=0.0500 \mathrm{~m}$, height $=0.0100 \mathrm{~m}$. The chamber held a total liquid volume of $20 \mathrm{~mL}$. During shearing over a $1 \mathrm{~h}$ period the temperature of the internal chamber was monitored with a $1 \mathrm{~mm}$ poly-tetraethylene (PTE) protected type (T) thermocouple, (RS Components, Ltd, UK) attached to a model 2006T temperature reader (RS Components, Ltd, UK). The temperature of the solution was maintained at $4^{\circ} \mathrm{C}$ throughout the experiment with an ice cooled water bath. A built-in tachometer monitored the speed of the rotating disc in (rpm) which was displayed on the USD power-pack made in house (Electrical Engineering Workshop, UCL, London). Figure 10 shows the dimensions of the USD shear device.

MFECP1 fusion protein stock solutions, $(20 \mathrm{~mL}, \sim 500$ $\mathrm{ng} / \mathrm{mL}$,) were sheared for $1 \mathrm{~h}$ at $10,000 \mathrm{rpm}$ at controlled and non controlled temperature $\left(4^{\circ} \mathrm{C}\right)$. Duplicate $100 \mu \mathrm{L}$ samples were taken at $0,300,600,1200,1800,2400,3000,3600$ seconds often initiating the shear and assayed by ELISA within $2 \mathrm{~h}$ of the start of the experiment. Each time a duplicate $100 \mu \mathrm{L}$ sample was taken it was replaced with equivalent volumes of un-sheared stock solution to maintain a consistent air/liquid interface.

\subsection{Air/Liquid Interface}

As well as shearing with no air, the USD device was able to shear protein samples with different percentage air/liquid interfaces. By filling the shear device with $10 \mathrm{~mL}$ of protein solution it was possible to generate a $50 \%$ air/liquid interface and with $15 \mathrm{~mL}$ of protein solution it was possible to generate a $25 \%$ air/liquid interface. Figure 8 shows a picture of the shear device with a $50 \%$ air/liquid interface. A plastic bottom plate was fabricated from transparent Perspex for easy visualisation from underneath.

\subsection{Deglycosylation}

MFECP1 fusion protein samples were deglycosylated by using the GlycoPro ${ }^{\mathrm{TM}}$ assay kit (Pro-zyme, USA). $10 \mu \mathrm{L}$ of reaction buffer was added to $5 \mu \mathrm{L}$ of all MFECP1 fusion protein samples that required deglycosylation. The samples were then mixed, incubated for 3 minutes at $95^{\circ} \mathrm{C}$ and centrifuged at $12,000 \mathrm{rpm}$. After this $10 \mu \mathrm{L}$ of reconstituted N-Glycosidase $\mathrm{F}$ buffer was added to all samples for $3 \mathrm{~h}$. Sample were analysed on the Agilent Bioanalyser after deglycosylation.

\subsection{Sandwich ELISA}

The Enzyme Linked Immunosorbent Assay (ELISA) used to analyse the MFECP1 fusion protein under investigation is described in [24]. Plates (NUNC 96 well Immunoplates Maxisorp, SLS, Denmark) were coated with $100 \mu \mathrm{L}$ of N-A1 $(1 \mu \mathrm{g} / \mathrm{mL})$ and incubated for $1 \mathrm{~h}$ at room temperature. N-A1 is the known functional domain on the carcinoma-embryonic antigen (CEA) that interacts with MFE-23 antibody fragment [2]. This domain was produced by fermentation at a final concentration of $0.5 \mathrm{mg} / \mathrm{mL}$, supplied by the Royal Free Hospital, (Oncology, UK). Control wells were coated with PBS only under the same conditions and emptied before blocking with milk proteins. All wells were blocked with 5\% milk proteins (Marvel Milk powder, UK)/PBS (150 $\mu \mathrm{L} /$ well) for $12 \mathrm{~h}$ to eliminated non-specific binding of proteins. Sheared MFECP1 fusion protein samples (100 $\mu \mathrm{L}$ samples) were applied and incubated for $1 \mathrm{~h}$, after which samples were removed and wells were washed with PBS solution. Detection of the intact MFECP1 fusion protein was carried out by incubating for $1 \mathrm{~h}$ with polyclonal anti- $\mathrm{CPG}_{2}$ primary antibody raised in rabbit, diluted $1 / 25,000$ in $1 \%$ milk proteins/PBS $(100 \mu \mathrm{L} /$ well), followed by incubation with anti-Horse Radish Peroxidase (anti-HRP) diluted 1/1,000 in $1 \%$ milk proteins/PBS $(100 \mu \mathrm{L} /$ well $)$. Washing steps consist of four washes with $0.1 \%$ Tween 20/PBS (v/v), followed by three PBS washes. Plates were developed with ophenylenediamine $\left(\mathrm{C}_{6} \mathrm{H}_{4}\left(\mathrm{NH}_{2}\right)_{2} \cdot 2 \mathrm{HCl}\right)$ in phosphate citrate buffer $\left(\mathrm{Na}_{2} \mathrm{HPO}_{4} .7 \mathrm{H}_{2} \mathrm{O}\right) \quad\left(\mathrm{C}_{6} \mathrm{H}_{8} \mathrm{O}_{7} . \mathrm{H}_{2} \mathrm{O}\right)$ with sodium perborate $\left(\mathrm{NaBO}_{3} \cdot \mathrm{H}_{2} \mathrm{O}\right),(100 \mu \mathrm{L} /$ well $)$ and the reaction was stopped after 3 minutes with $4 \mathrm{M} \mathrm{HCl},(100 \mu \mathrm{L} /$ well $)$. Optical density was measured at $490 \mathrm{~nm}$ on an Opsys MR ELISA plate reader (Dynex Technologies Limited, UK). The sandwich ELISA worked by producing the response when intact MFECP1 fusion protein was present. To calculate the approximate concentration of intact MFECP1 fusion protein in the sheared samples, a calibration curve was set up. Absorbance's were measured at $490 \mathrm{~nm}$ of serial stock solutions from $700-31 \mathrm{ng} / \mathrm{mL}$ producing a calibration line giving a predictable relative error of $+/-10 \%$. Control experiments showed fragments of the fusion did not give responses and no other false positives were produced when wells were not coated with NA1 the antigen for (ScFv) MFE.

\section{Results and Discussion}

\subsection{Characterisation of the MFECP1 Fusion Protein}

Firstly it was important to know the composition of the purified MFECP1 fusion protein to be tested. Shearing protein solutions with a range of variants (e.g glycosylated 
variants) could give very complicated results. Biomolecules of different structures interact with process conditions in different ways. For example, [18] showed for plasmids the extent of shear damage increased with plasmid size. Biological variation in recombinant protein species is common, for example proteins produced by Pichia pastoris expression systems can vary as a consequence of unpredictable glycosylation [21]; this variation may not be apparent on electrophoretic gels as molecular weight differences are too small.

\subsection{Bioanalyser}

A modern analytical technique was used to characterise any variations in the protein solution that were under investigation. The Agilent Bioanalyser Protein 210 chip system was used to detect all fragments that may be present in the protein solutions that would be used in the shear studies. This new technique separated proteins by size to charge ratio similar to SDS-PAGE, however the technology also allows protein analysis in one tenth of the time with detailed electrographs (figure 1) shows possible fragments and glycosylated fragments that are too small to be seen on a convention SDS PAGE protein analysis. Purified MFECP1 fusion protein produced on the large scale was applied to the Bioanalyser Protein 210 chips. The electrograph shows that the MFECP1 fusion protein contained a heterogeneous array of products (figure 1 (i)) with four protein species present. The electrograph shows that there are two large proteins at 87 and $80 \mathrm{kDa}$ and two smaller proteins at 54 and $48 \mathrm{kDa}$. The MFECP1 fusion protein has a total molecular weight of $\sim 70$ $\mathrm{kDa}$ as determined on SDS-PAGE by the Royal Free Hospital, (London, UK). This is made up of $27 \mathrm{kDa}$ for the MFE-23 fragmentn $\mathrm{ScFv}, 42 \mathrm{kDa}$ for the carboxypeptidase enzyme, $\sim 2 \mathrm{kDa}$ for the hexa-histidine-tag $\left(\mathrm{His}_{6}\right)$, leader protein sequences and glyscosylation sugars. Hence the larger species at $80 \mathrm{kDa}$ and $87 \mathrm{kDa}$ were thought to be glycosylated variants of the MFECP1 fusion protein. The other proteins at $54 \mathrm{kDa}$ and $48 \mathrm{kDa}$ were thought to be fragmented fusion protein, most likely to be $\mathrm{CPG}_{2}$ fragments. This is consistent with other published work as mannose glycosylation can add several $\mathrm{kDa}$ to a recombinant MFECP1 fusion protein species [21].
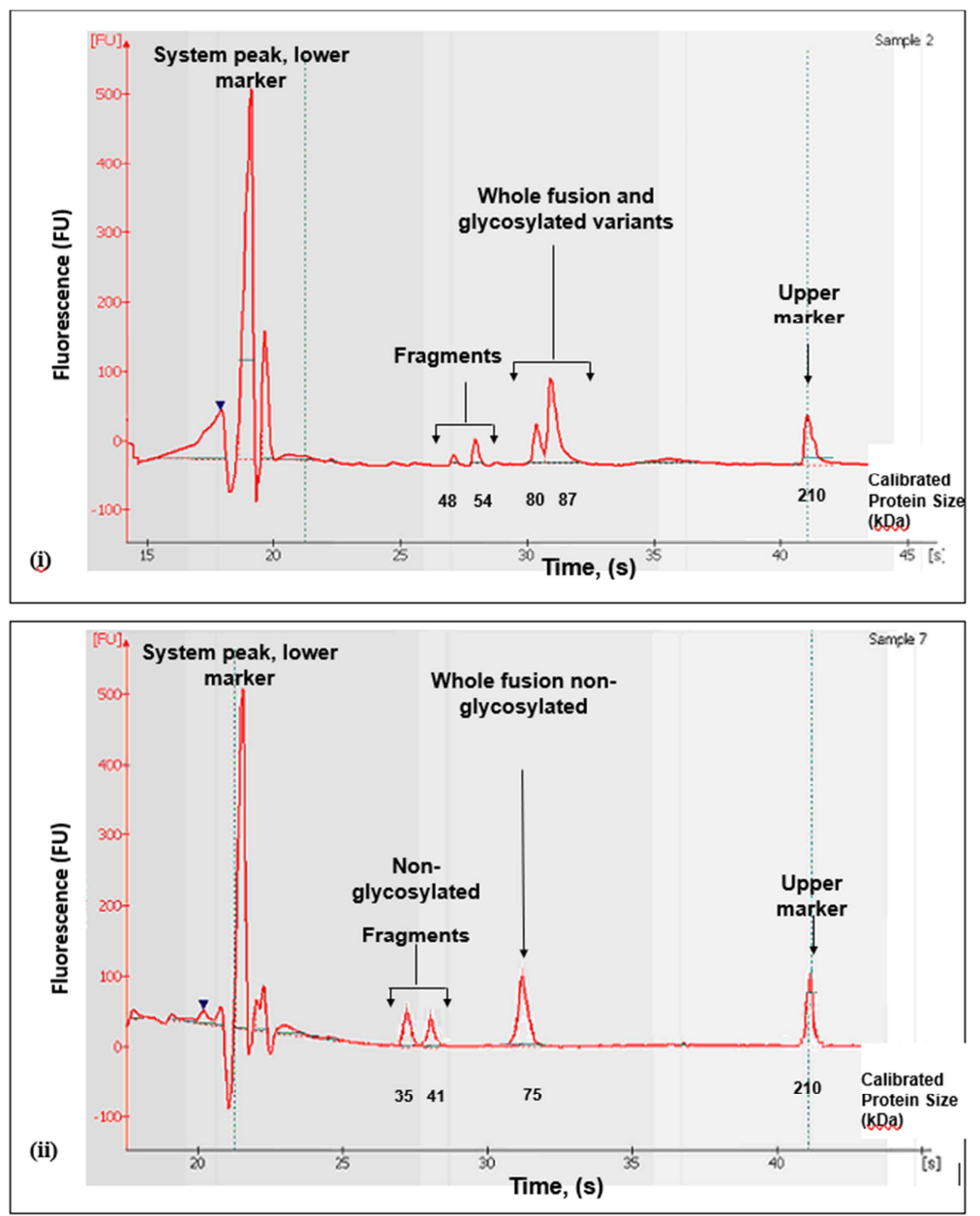

Figure 1. The analysis of purified MFECP1 fusion protein on the Agilent Bioanalyser showing the effect of deglycosylation on protein profile. $4 \mu$ L of protein was analysed on the Bioanalyser: (i), before deglycosylation and (ii), after deglycosylation. Bioanalyser chips were run under non-reducing conditions. Calculated areas (by peak mass): whole fusion glycosylated variants $=0.0042 \mathrm{~g} ;$ Fragments $=0.0010 \mathrm{~g}$. Hence $81 \%=$ glycosylated fusion variants; $19 \%=$ fragments. 
were deglycosylated using a fixed protocol from GlycoPro ${ }^{\mathrm{TM}}$ assay kit (Pro-zyme, USA) (see Materials and Methods) and then were analysed on the Bioanalyser to observe any difference in protein profiles. The Bioanalyser analysis of MFECP1 fusion protein solutions after the deglycosylation procedure showed that protein peaks at $87 \mathrm{kDa}$ and $80 \mathrm{kDa}$ were different glycosylated forms of the MFECP1 fusion protein (figure 1 (ii)). The results show that these two larger protein peaks generated a single protein at $75 \mathrm{kDa}$ which is more likely to be the whole MFECP1 fusion protein lacking mannose sugars. Experiments showed that the peaks at 48 and $54 \mathrm{kDa}$ evolved into peaks at 35 and $41 \mathrm{kDa}$ (figure 1 (ii)) after deglycosylation and hence could be differently glycosylated forms of the $\mathrm{CPG}_{2}$ fragment of the MFECP1 fusion protein, as this enzyme has a molecular weight of around $42 \mathrm{kDa}$. These experiments were important because they demonstrated the presence of MFECP1 fusion protein variants and fragments within the protein solution which could affect the rates of protein degradation and loss during shear experiments [23].

Peak areas analysed from the Bioanalyser showed that a typical MFECP1 fusion protein batch (after all downstream purification steps) contains $81 \%$ intact MFECP1 fusion protein and $19 \% \mathrm{CPG}_{2}$ fragments. Conclusions from the results show that a specific assay will be required to measure accurately intact MFECP1 fusion protein for shearing experiments. This is important because a non-specific assay would detect fragments already in the sample which were not generated during shear conditions.

\subsection{ELISA}

It was important to measure over shearing time how much MFECP1 fusion protein was being degraded under different conditions. This is because the MFECP1 fusion protein preparation contained heterogeneous protein products as seen in figure 1 (i), a specific assay was required to measure how much protein was being degraded. Several benefits can explain why an ELISA detection technique should be used in the measurement of intact MFECP1 fusion protein over other techniques like enzyme assays or the Bradford assay [8]. The advantages of using an ELISA over these other techniques include specificity, quantification down to $\mathrm{ng} / \mathrm{mL}$, small sample volume required and ease of assay operation. The ELISA developed by the Royal Free Hospital, Department of Oncology (London, UK) used a specific antigen (NA1) that detects only intact MFECP1 fusion protein, further justifying the use of this analytical technique.

A non-quantitative ELISA existed whereby samples were compared by serial dilution and absorbance measurements at $490 \mathrm{~nm}$. The aim next was to utilise this existing ELISA protocol to generate a mathematical relationship that would allow the accurate quantification of intact MFECP1 fusion protein from samples of unknown concentration when only the response is known.

The concentration of intact MFECP1 fusion protein was determined using an ELISA. Figure 2 shows the relationship between intact MFECP1 fusion protein concentration and the absorbance at $490 \mathrm{~nm}$. After adjusting for the background absorbance of 0.09 , a standard curve was established using a $\log -\log$ graph. This was found to give a good linear correlation in the range of $31 \mathrm{ng} / \mathrm{mL}$ and $700 \mathrm{ng} / \mathrm{mL}$ (Figure 3), outside of which linearity was lost and the protein concentration measured would not be accurate.

However, in samples subjected to shear stress the concentration of intact MFECP1 fusion protein needed to be determined in the presence of the protein subunits, $\mathrm{CPG}_{2}$ and MFE. It was therefore important to establish whether these subunits can undergo non-specific binding which would result in false positives when using this assay. For this known concentrations of purified subunits were substituted to the ELISA protocol. In addition, a negative control was set up to test whether MFECP1 fusion protein would non-specifically bind to wells not coated with the NA1 antigen. Figure 4 shows that there are no non-specific binding for either subunit using this ELISA protocol, and free $\mathrm{CPG}_{2}$ or MFE-23 will therefore not give false positive results, or interfere with intact MFECP1 fusion protein concentration measured in sheared samples. Also, the intact MFECP1 fusion protein can only be detected when wells are coated with the NA1 antigen (Figure 4).

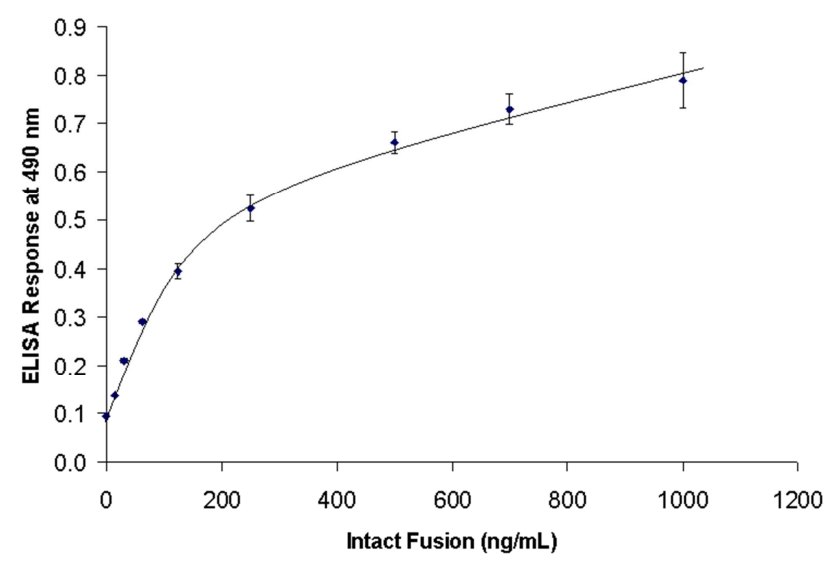

Figure 2. Shows the calibration curve of MFECP1 fusion protein standards. Absorbance responses readings were measured at $490 \mathrm{~nm}$ in a 96 well micro-well plate. Line shown is best fit drawn by eye.

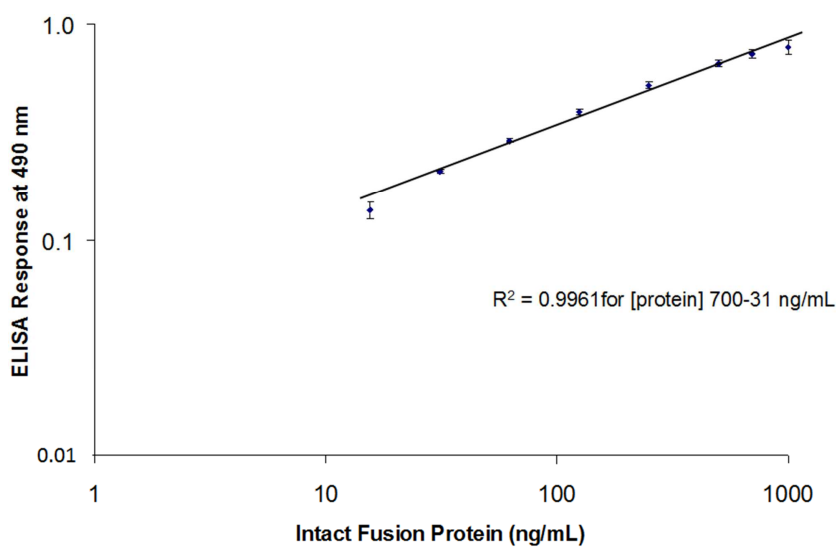

Figure 3. Calibration graph for ELISA analysis obtained using a log by log plot. Protein concentrations ranging from 700-31 $\mathrm{ng} / \mathrm{mL}$ can be measured with an error of ${ }^{+} /-10 \%$. Line shown is best least square fit. 


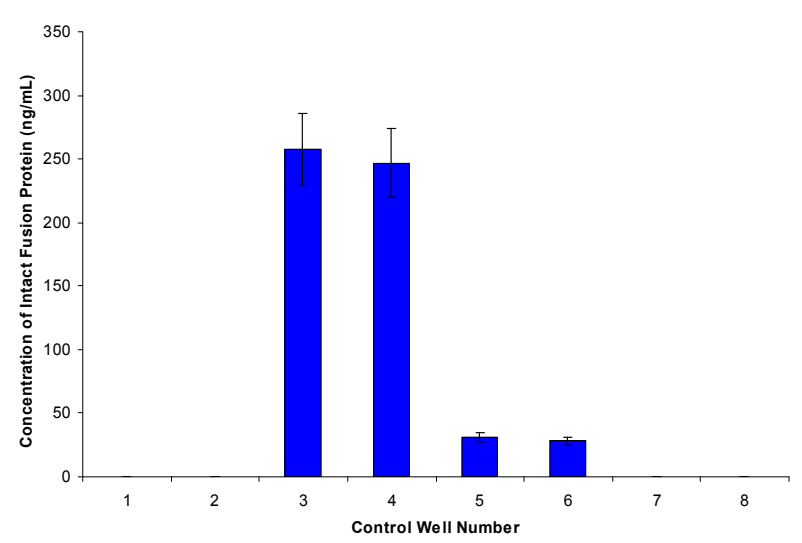

Figure 4. Determination of non-specific binding of ELISA assay. ELISA plates were coated with NA1 antigen (wells 1-6) to which the following was added: 1, $C P G_{2} 1.25 \mathrm{U} / \mathrm{mL} ; 2, M F E, 1 \mu \mathrm{g} / \mathrm{mL} ; 3, M F E C P 1,250 \mathrm{ng} / \mathrm{mL} ; 4$, MFECP1, $250 \mathrm{ng} / \mathrm{mL} ; 5, \mathrm{MFECP} 1,31 \mathrm{ng} / \mathrm{mL} ; 6, \mathrm{MFECP} 1,31 \mathrm{ng} / \mathrm{mL}$. In addition, two negative control samples were measured by coating with $P B S$ and adding MFECP1, $500 \mathrm{ng} / \mathrm{mL}$ (wells 7 and 8). The protein concentration detected was calculated using the standard curve (figure 3 ).

\subsection{Specification of the Use of the USD Shear Device}

Initial experiments that exposed how the protein behaved in a shear field could begin because a reliable quantification method was developed to accurately measure the amount of MFECP1 fusion protein present in samples. Initially, the integrity of the MFECP1 protein in a $500 \mathrm{ng} / \mathrm{mL}$, stock solution was monitored over a $1 \mathrm{~h}$ period at $10,000 \mathrm{rpm}$ in the USD shear device at room temperature. The results in figure 5 showed that degradation was occurring (solid circles), however it was thought that this degradation was due, at least in part, to the significant temperature increase (upto $\sim 55^{\circ} \mathrm{C}$ ) of the process fluid in the device. This conclusion was confirmed as results in figure 5 (open squares) show that loss of protein integrity was reduced considerably by the addition of a cooling system to the exterior of the device.

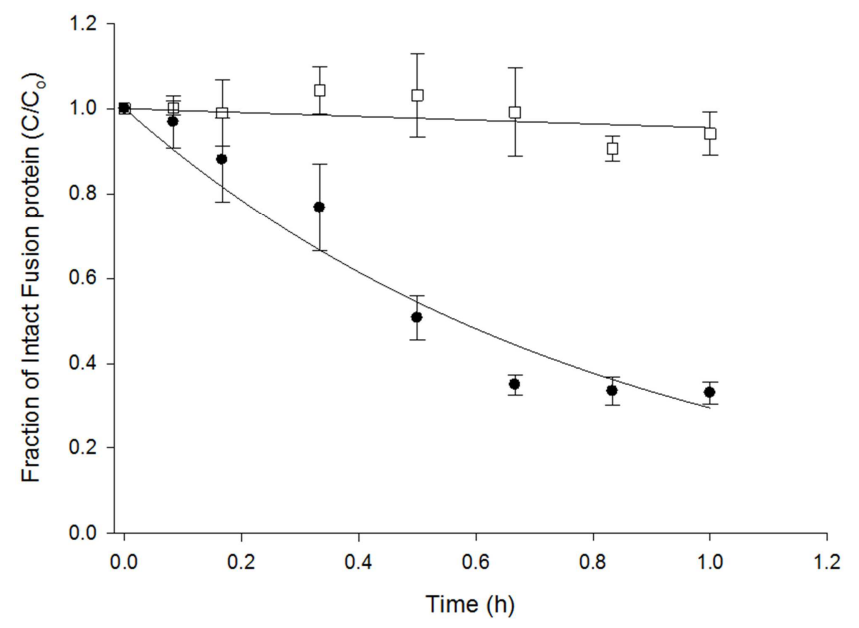

Figure 5. The effect of increasing temperature and shear on fusion protein degradation. $20 \mathrm{~mL}$ of MFECP1 fusion protein solution was sheared for $1 \mathrm{~h}$ in a USD shear device. Experimental conditions were, 10,000 rpm: (- $\square-$ ), $C_{o}=451 \mathrm{ng} / \mathrm{mL}$, no cooling system and ( $\left.\square-\right), C_{o}=455 \mathrm{ng} / \mathrm{mL}, 10,000 \mathrm{rpm}$ : with ice bath cooling system; $C_{o}=$ initial concentration of intact MFECP1 fusion protein as measured by ELISA.

Results in figure 6 show how temperature increased inside and outside the device. This increase was not desirable as two variables in the shear experiment were changing at the same time, in this case the amount of shear and temperature. The addition of a thermocouple in the device's base plate allowed more accurate measurements of the internal fluid temperature. The temperature monitoring showed that the use of an ice cooled water bath prevented temperature increase when the USD shear device was operated at 5,000 rpm. Figures 6 and 7 show how the temperature increased inside the shear device, and how temperature was affected with and without a cooling system. These speeds correspond to energy dissipations that are equivalent to events observed during large-scale production, during pumping and within disc-stack centrifuges. [7, 33].

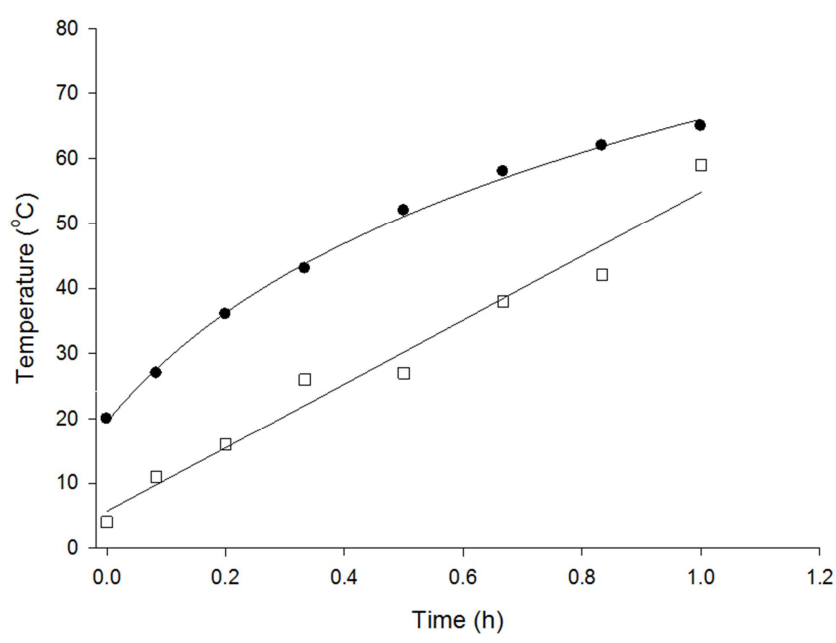

Figure 6. Shows the temperature increase inside and outside of the shear device. Shear device was run for $1 \mathrm{~h}$ at 10,000 rpm. (- - -), temperature of the outside walls of the shear device and ( $\square-)$, temperature of the process fluid inside the device. Temperatures of process fluid and walls of the device were measured with a mercury thermometer.

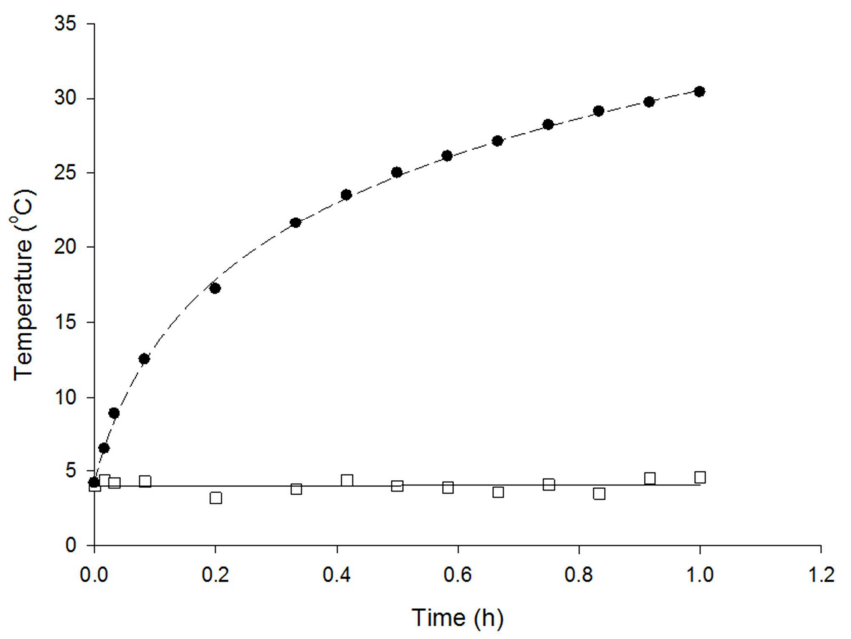

Figure 7. Shows the temperature increase of the process fluid inside the shear device with and without ice bath cooler. Shear device was run for 1 h at 5,000 rpm. (-- --), without ice bath cooler and (- - ), with ice bath cooler. During shearing over a $1 \mathrm{~h}$ period temperature of the internal chamber was monitored with a $1 \mathrm{~mm}$ poly tetra fluro ethylene (PTE) protected type (T) thermocouple, 
(RS Components, Ltd, UK) which was attached to a model 2006T, temperature reader (RS Components, Ltd, UK). Lines of fit drawn by eye.

\subsection{Visualization of an Air Liquid Interface in a USD Device}

In order to ensure excess liquid was not escaping from the device and to monitor the process fluid during experiments a transparent Perspex bottom plate was manufactured (Mechanical Workshop, UCL, UK). This allowed visual monitoring of the process fluid during shear experiments. Water was treated with a green dye for easy visualization. Such observations identified that fluid was escaping into the motor cavity by centrifugal forces. This problem was corrected by the addition of a PTFE seal. The seal had a life time of approximately $20 \times 1 \mathrm{~h}$ shear runs and required replacing once worn out. The observations also showed how process solution was being lost through the top of the device. As a result of these findings a way of reducing fluid loss was implemented by the addition of a tapered top inside the chamber, just above the disc. This allowed the circulating process solution to stay in the device and not escape readily into the motor cavity. Figure 8 (i-vii) shows how the process fluid flows in the shear device when running at 5,000 rpm. The green dye shows how the liquid is flung out to the sides of the device by the centrifugal forces imposed by the rotating disc. Different volumes of liquid could be removed from the device in order to generate different percentage air/liquid interfaces. Figure 9 (i) shows the formation of an air/liquid interface within the rotating disc device with a stable central core of air. Figure 9 (ii) shows a Computational Fluid Dynamics (CFD) simulation of the predicted shape of the interface. Figure 10 (i) shows the dimensions of the device, figure 10 (ii) shows CFD simulations of how the fluid flows and where the highest shear regions are predicted to be respectively, shown by red arrows, lowest shear stress with blue arrows. The results show that the fluid moves in a circular motion away from the disc which was later confirmed by experimental observation. The key aspect to note here is that the high shear region at the tips of the discs seems to correspond to the position of the air/liquid interface in figure $8(\mathrm{v})$ when $10 \mathrm{~mL}$ of fluid is removed.

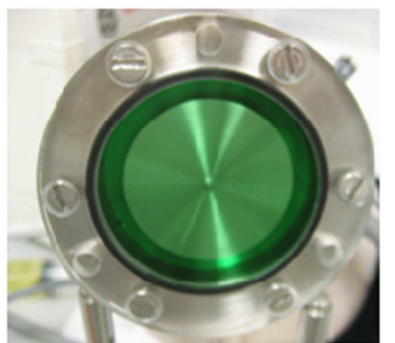

(i)

$0 \mathrm{~mL}$

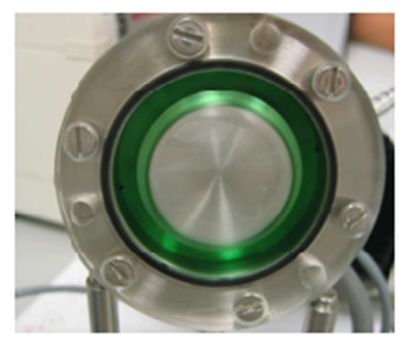

(iv) $\quad-9 \mathrm{~mL}$

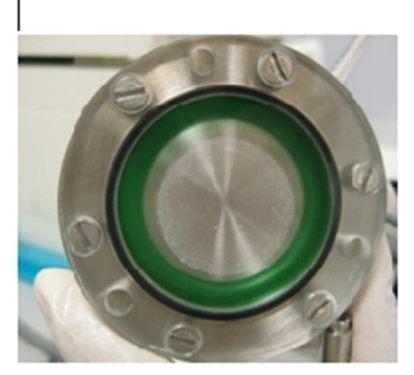

(vii) $-12 \mathrm{~mL}$

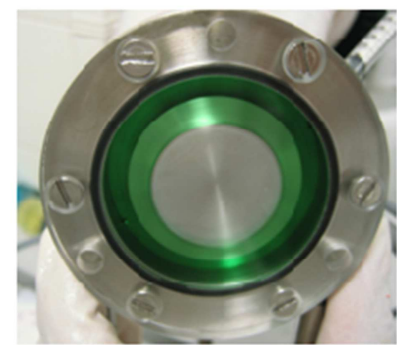

(ii) $\quad-7 \mathrm{~mL}$

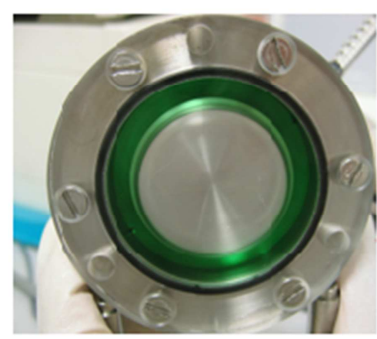

(v)

$-10 \mathrm{~mL}$

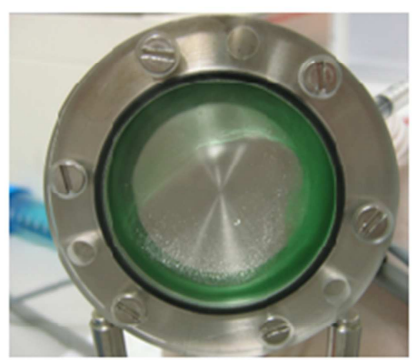

(viii) $-13 \mathrm{~mL}$

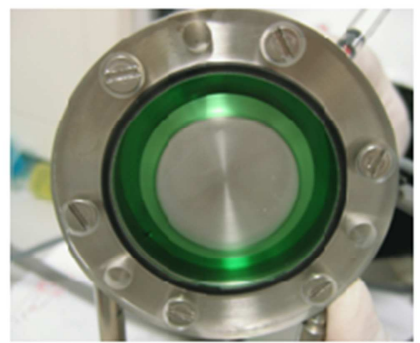

(iii) $\quad-8 \mathrm{~mL}$

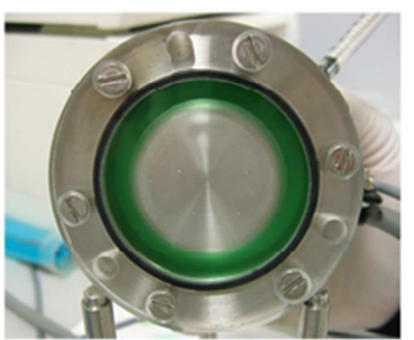

(vi)
$-11 \mathrm{~mL}$

Figure 8. Shows the air/liquid interface to chaotic behaviour in a rotating disc shear device at 5,000 rpm. Water was coloured with green food colouring to observe how the air/liquid interface behaves and where it resides. Zero $\mathrm{mL}$ of liquid removed, (i); $7 \mathrm{~mL}$ removed, (ii); $8 \mathrm{~mL}$, (iii); $9 \mathrm{~mL}$, (iv) $10 \mathrm{~mL}$, (v); $11 \mathrm{~mL}$, (vi); $12 \mathrm{~mL}$, (vii); $13 \mathrm{~mL}$, (viii)=unstable. The pictures show that an area of air interface was achievable within the centre of the shear device. Pictures were taken with a digital camera, (Sony, 5.0 Mega pixel, Japan). 


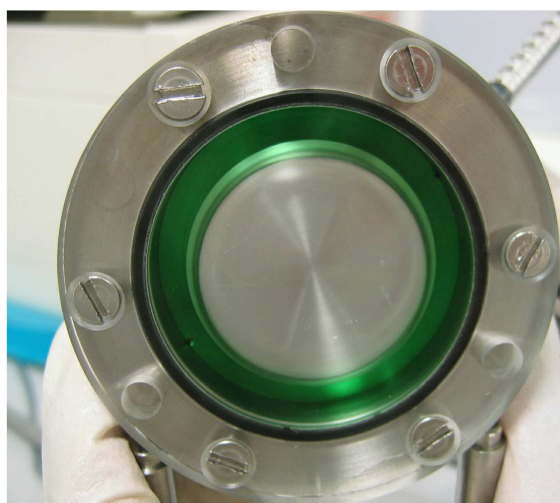

(i)

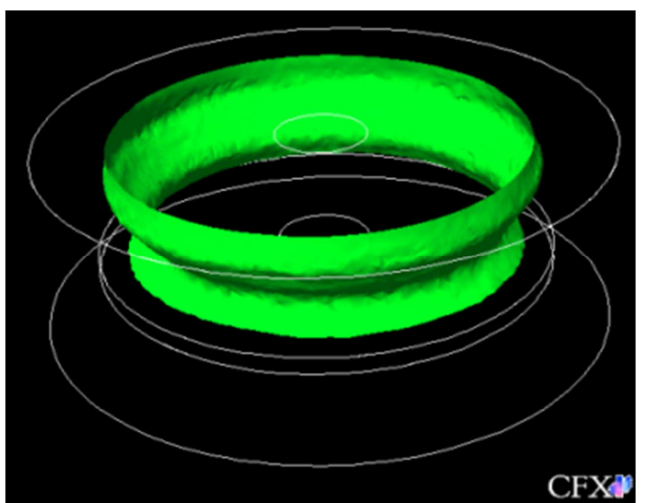

(ii)

Figure 9. Characterisation of an air/liquid interface in the shear device. (i), Shows how $10 \mathrm{~mL}$ of fluid coloured with green dye actually flows in the shear device during operation at 5,000 rpm; (ii) shows the result of modelling air /liquid distribution using a CFX program.

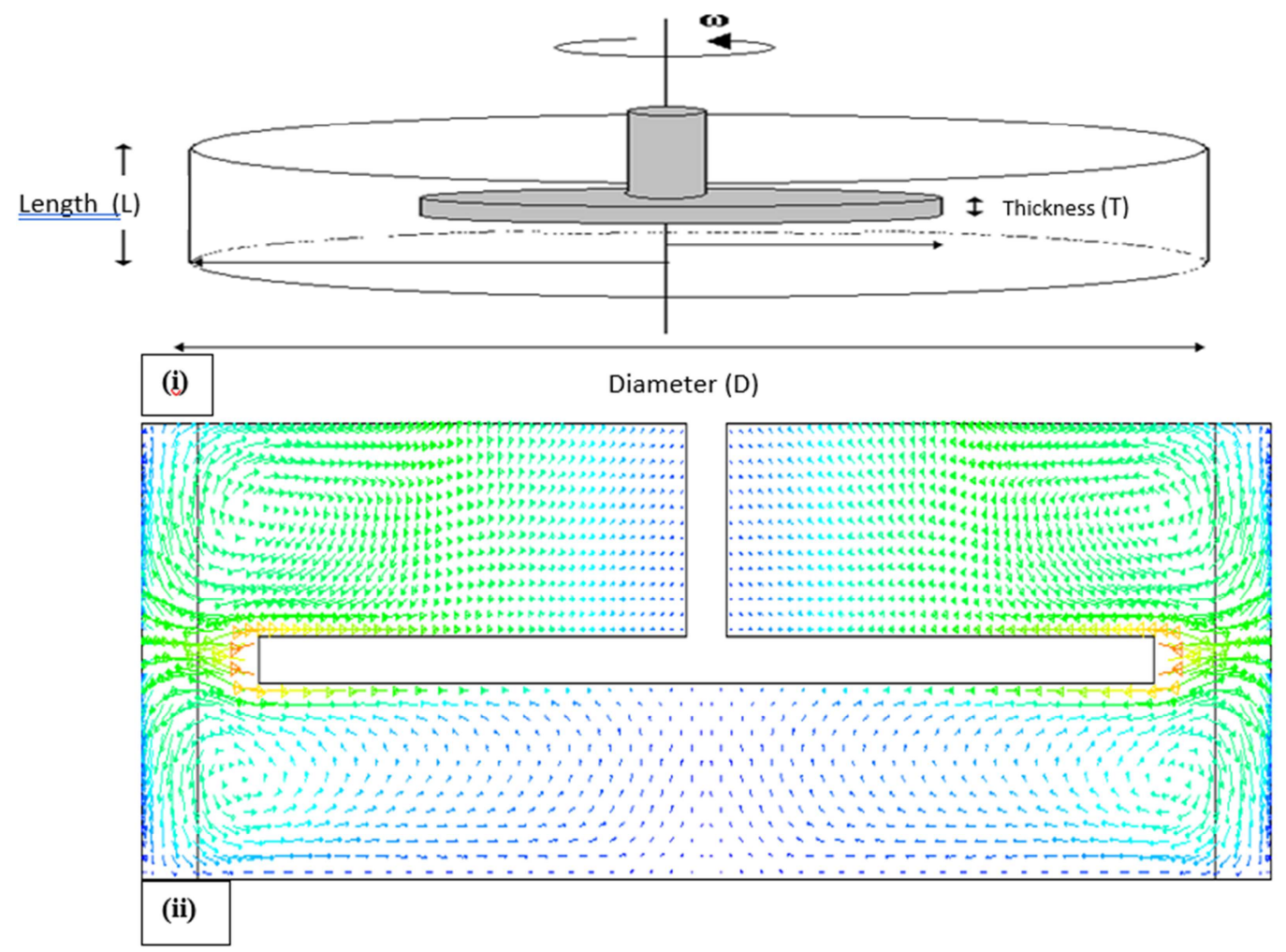

Figure 10. Dimensions of the ultra scale-down shear device and CFX computer simulation of the air/liquid interface. (i), a diagram of the shear device with dimensions of the spinning disc where the radius of disc, $R=0.020 \mathrm{~m}$, thickness of disc $T=0.0015 \mathrm{~m}$, diameter of the internal chamber $D=0.050 \mathrm{~m}$, length of internal chamber $L=0.010 \mathrm{~m}$. The device holds a total volume of $20 \mathrm{~mL}$; (ii) CFD model of how fluid might flow, arrows indicate direction and force vectors.

\subsection{Modelling the Rate of Protein Degradation}

During the manufacture, production and purification stages of biopharmaceuticals, proteins can be affected by high shear forces or by shear associated effects such that their structure and integrity is altered, resulting in degradation. This process is often quantified by using a first order degradation model as described in [23] i.e with protein degradation being described by a first order rate equation. One possible reaction scheme is given in equation (1), where $C$ is the concentration of the active protein, $U$ is the concentration of the degraded protein, $k_{1}$ is the rate of protein degradation and $k_{2}$ is the rate of active protein regeneration if the reaction is reversible:

$$
C \stackrel{k_{1}}{\underset{k_{2}}{\rightleftarrows}} U
$$

We may assume $[U]_{0}=0$ at time, $t=0$. The rate of change of $C$ with respect to time maybe given by equation (2) which when integrated and rearranged gives equation (3),

$$
\begin{gathered}
\frac{d[C]}{d t}=-k_{1} \cdot[C]+k_{2} \cdot[U] \\
\frac{[C]}{[C]_{0}}=\frac{k_{2}}{k_{1}+k_{2}}+\frac{k_{1}}{k_{1}+k_{2}} \cdot e^{-\left(k_{1}+k_{2}\right) t}
\end{gathered}
$$




$$
\frac{[C]}{[C]_{0}}=a+b e^{-k t}
$$

where the constants $a, b$ and $k$ are:

$$
\begin{aligned}
& a=\frac{k_{2}}{k_{1}+k_{2}} \\
& b=\frac{k_{1}}{k_{1}+k_{2}} \\
& k=k_{1}+k_{2}
\end{aligned}
$$

Equations (4) is a simplified version of equation (3), where the constants a, b, and $\mathrm{k}$ are equations (5), (6) and (7) respectively.

This first order relationship was used to fit all data in shear experiments generating a net rate constant, $k, \mathrm{~h}^{-1}$ for each experimental condition. Curves were fitted to the data using the non-linear regression wizard of Sigma Plot 9.0 (SSI, California, USA). The wizard in Sigma Plot derives the best least square fit based on the Levenberg-Marquardt (LM) algorithm. As $t \rightarrow \infty$ the final equilibrium concentration ratio $[C]_{\infty} /[C]_{0} \rightarrow a$, (equation 4 ). Rate constants in $\mathrm{h}^{-1}$ and the final equilibrium concentrations values, $[C]_{\infty}$, in $\mathrm{ng} / \mathrm{mL}$ can then be reported within the figures.

\section{Conclusion}

In conclusion it has been shown that a USD shear device can be used to characterise antibody fusion proteins in controlled conditions. It has been described that the fusion protein under investigation contained a glycosylated variant and deglycosylation experiments showed that a more refined fusion protein product could be used in shear experiments, reducing variability in experiments. The ELISA was the optimum analytical technique to quantify the amount of intact fusion protein giving a $\mathrm{R}^{2}$ value of 0.9961 for protein concentrations between $700-31 \mathrm{ng} / \mathrm{mL}$. It was found that using high rpm above 10,000 increased the temperature of the shear device, however this problem was corrected by using a lower rpm (5000) with an ice cooled water bath. Lastly consistently controlled air/liquid interfaces could be generated in the shear device, showing that it could be used effectively to characterise the fusion protein interacting with these conditions and shear. Future work could uncover protecting agents that can be added with in the shear device and potentially could give a process engineer insight of how to improve the large scale manufacture of fusion proteins to increase yields and reducing protein deactivation.

\section{Acknowledgements}

The present worldwide publication is wholly dedicated in honour of my late mother and father, Baljinder Kaur Blas and Ram Blas who both passed away during the course of my $\mathrm{PhD}$. It is also dedicated to my beautiful children, Leah Sophie and Theodore Colin Blas who inspire me to achieve the very best in life. I would also like to thank my fiancée Miss Tiffany Amelia Greenwood, your unconditional love and support means the world to me. Furthermore I would like to thank the following scientists for their trust, guidance and the opportunity to complete this study:

Professor Gary Lye (Head of Department, Biochemical Engineering at UCL).

Professor Nigel Titchener-Hooker (Dean of Faculty of Engineering Sciences at UCL).

Professor Kerry Chester (Research Department of Oncology, Cancer Institute, UCL).

Professor John Ward (Synthetic Biology for Bioprocessing, UCL).

Professor John Mitchell (Communications Systems Engineering, Vice Dean Education, UCL).

Professor Nik Willoughby of Bioprocessing, (Heriot-Watt University).

Professor Mike Hoare, (Department of Biochemical Engineering UCL).

\section{References}

[1] Bagshawe, D. K. Antibody directed enzyme prodrug therapy (ADEPT). 1989, Br. Jr Cancer, 60, 275-281.

[2] Begent, R. H. J.; Verhaar, M. J.; Chester, K. A.; Casey, J. L.; Green, A. J.; Napier, M. P.; Hope-Stone, L. D.; Cushen, N.; Keep, P. A.; Johnson, C. J.; Hawkins, R. E.; Hilson, A. J. W.; Robson, L. 1996, Clinical evidence of efficient tumor targeting based on single-chain $\mathrm{fv}$ antibody selected from a combinatorial library. Nature Medicine, 9, 979-984.

[3] Bekard, B, I.; and Dunstan, E, D. (2009) Shear-Induced Deformation of Bovine Insulin in Couette Flow. J. Phys. Chem. B, 113, 8453-8457.

[4] Biddlecombe, G. J.; Craig, V. A; Zhang, H.; Uddin, S.; Mulot, S.; Fish, C. B.; Bracewell, G. D. 2007, Determining Antibody Stability: Creation of Solid-Liquid Interfacial Effects within a High Shear Environment. Biotechnology Progress 23, 12181222 .

[5] Blas, P; Tolner, B; Ward, J; Chester, K; Hoare, M (2018) The Use of a Surface Active Agent in the Protection of a Fusion Protein during Bioprocessing. Biotechnol. Bioeng. 115, 11.

[6] Blas, P. 2019. Improving-the-Bioprocessing-of-ADEPTFusion-Proteins-using-Ultra-scale-down-techniques. Journal of bioengineering 1, 25-46.

[7] Boychyn, M.; Yim, S. S. S.; Shamlou, P. A.; Bulmer, M.; More, J.; Hoare, M. 2001, Characterization of flow intensity in continuous centrifuges for the development of laboratory equipment mimics, Chem. Eng. Sci. 56, 4759-4770.

[8] Bradford, (1976). A rapid and sensitive method for the quantitation of microgram quantities of protein utilizing the principle of protein-dye binding. Anal. Biochem. 72, 248-254.

[9] Charm, S. E.; Lai, C. J. 1971, Comparison of ultrafiltration systems for concentrations of biologicals. Biotechnol. Bioeng. $13,185-202$.

[10] Charm, S. E.; Wong, B. L. 1970, Enzyme inactivation with shearing. Biotechnol. Bioeng. 7, 1103-1109. 
[11] Chattopadhyay, D.; Rathman, J. F.; Chalmers, J. J. 1994, The protective effect of specific medium additives with respect to bubble rupture. Biotechnol. Bioeng. 45, 473-480.

[12] Damodaran, S. 2003, In situ measurements of conformational changes in proteins at liquid interfaces by circular dichroism spectroscopy. Anal. Bioanal. Chem. 376, 182-188.

[13] Duerkop, M.; Berger, E.; Dürauer, A.; Jungbauer, A. (2018) Impact of Cavitation, High Shear Stress and Air/Liquid Interfaces on Protein Aggregation. Biotechnology Journal 13, 7.

[14] Goswami, S, Wang, W; Arakawa, T and Ohtake, S. 2013, Developments and Challenges for mAb-Based Therapeutics. Antibodies 2, 452-500.

[15] Harrison, J. S.; Gill, A.; Hoare, M. 1998, Stability of a singlechain $\mathrm{fv}$ antibody fragment when exposed to high shear environment combined with air-liquid interfaces. Biotechnol. Bioeng. 59, 517-519.

[16] Jeffrey, C. K.; Wei, S.; Priyanka, K.; Mostafa, K.; Xiaoli, W.; Yang, S.; Raimund, J. O.; and Ward, S. E. (2019) Engineering a HER2-specific antibody-drug conjugate to increase lysosomal delivery and therapeutic efficacy. Nature Biotechnology volume 37, 523-526.

[17] Lencki, R. W.; Tecante, A.; Choplin, C. 1993, Effect of shear on the inactivation kinetics of the enzyme dextransucrase. Biotechnol. Bioeng. 42, 1061-1067.

[18] Levy, M. S.; Collins, I. J.; Yim, S. S.; Ward, J. M.; TitchenerHooker, N. J.; Shamlou, P. A.; Dunnill, P. 1999, Effect of shear on plasmid DNA in solution. Bioprocess Engineering, 20, 7-13.

[19] Maa, Y. F.; Hsu, C. C. 1996, Effect of high shear on proteins. Biotechnol. Bioeng 51, 458-465.

[20] Maa, Y. F.; Hsu, C. C. 1997, Protein denaturation by combined effect of shear and air-liquid interface. Biotechnol. Bioeng 54, 503-512.

[21] Medzihradszky, K, F.; Spencer, D, I.; Sharma, S, K.; Bhatia, J.; Pedley, R, B.; Read, D, A.; Begent, R, H.; Chester, K, A. (2004). Glycoforms obtained by expression in Pichia pastoris improve cancer targeting potential of a recombinant antibodyenzyme fusion protein. Glycobiology. 14, 27-37.

[22] Michael, P. N.; Chester, K. A.; Melton, R. G.; Robson, L.;
Nicholas, W.; Boden, J. A.; Pedley, R. B.; Begent, R. H. J.; Sherwood, R. F.; Minton, N. P. 1996, In vitro and in vivo characterisation of a recombinant carboxypeptidase $\mathrm{G}_{2}$ : anti$\mathrm{CEA} \mathrm{scF} v$ fusion protein. Immuntechnology 2, 47-57.

[23] Oliva, A.; Santovena, A.; Farina, J.; Llabres, M. 2003, Effect of high shear rate on stability of proteins: Kinetinc study. J. Pharm. Biomed. Anal. 33, 145-155.

[24] Pedley, R. B,; Sharma, S. K.; Hawkins, R. E.; Chester, K. A. 2003, Antibody directed enzyme prodrug therapy. Method in molecular medicine. 90 491-515.

[25] Rayat, C, M, E.; Chatel, A.; Hoare, M.; Lye, J. G. 2016, Ultra scale-down approaches to enhance the creation of bioprocesses at scale: impacts of process shear stress and early recovery stages. Current Opinion in Chemical Engineering. $14,150-157$.

[26] Thomas, C. R.; Dunnill, P. 1979, Action of shear on enzymes: Studies with catalase and urease. Biotechnol. Bioeng. 11, 2279-2302.

[27] Thomas, R. C.; Geer, D. 2011, Effects of shear on proteins in solution. Biotechnology Letters 33, 443-456.

[28] Titchener-Hooker, N, J.; Dunnill, P.; Hoare, M (2008) Micro biochemical engineering to accelerate the design of industrialscale downstream processes for biopharmaceutical proteins. Biotechnol. Bioeng, 100, 473-487.

[29] Tirrell, M.; Middleman, S.; Shear modification of enzyme kinetics. Biotechnol. Bioeng. 1975, 17, 299-303.

[30] Tolner, B.; Smith, L.; Begent, R. H. J.; Chester, K. A. 2006.(a) Production of recombinant protein in Pichia pastoris by Fermentation. Nature Protocols. 1, 1006-1021.

[31] Tolner, B.; Smith, L.; Begent, R. H. J.; Chester, K. A. 2006.(b) Expanded-bed adsorption immobilized-metal affinity chromatography. Nature Protocols. 1, 1213-1222.

[32] Vikar, P. D.; Narendranathan, T. J.; Hoare, M.; Dunnill, P. 1981, Studies of the effects of shear on globular proteins: Extentions to high shear fields and to pumps. Biotechnol. Bioeng. 23, 425-429.

[33] Yim, S, S.; Shamlou, P, A. (2000). The engineering effects of fluid flow on freely suspended biological macro-materials and macromolecules. Advances in Biochem Eng. 67, 83-121. 